\title{
BMJ Open Active commuting and leisure-time physical activity among adults in western Nepal: a cross-sectional study
}

\author{
Susan Paudel (D) , ${ }^{1}$ Narayan Subedi (D) , ${ }^{1,2}$ Craig S McLachlan, ${ }^{3}$ Ben J Smith (D) , ${ }^{4}$ \\ Per Kallestrup (1) , ${ }^{5}$ Dinesh Neupane (1) ${ }^{1,6}$
}

To cite: Paudel S, Subedi N, McLachlan CS, et al. Active commuting and leisure-time physical activity among adults in western Nepal: a crosssectional study. BMJ Open 2021;11:e051846. doi:10.1136/ bmjopen-2021-051846

- Prepublication history for this paper is available online. To view these files, please visit the journal online (http://dx.doi. org/10.1136/bmjopen-2021051846).

Received 30 March 2021 Accepted 28 July 2021

Check for updates

(c) Author(s) (or their employer(s)) 2021. Re-use permitted under CC BY-NC. No commercial re-use. See rights and permissions. Published by BMJ.

${ }^{1}$ Nepal Development Society, Bharatpur, Bagmati, Nepal

${ }^{2}$ School of Exercise and Nutrition Sciences, Deakin University Faculty of Health, Burwood, Victoria, Australia

${ }^{3}$ Torrens University Australia-

Sydney Campus Pyrmont,

Pyrmont, New South Wales,

Australia

${ }^{4}$ The University of Sydney,

Sydney, New South Wales,

Australia

${ }^{5}$ Center for Global Health, Department of Public Health, Aarhus University, Aarhus, Denmark

${ }^{6}$ Department of Epidemiology, Johns Hopkins University, Baltimore, Maryland, USA

Correspondence to

Narayan Subedi;

subedi.narayan@gmail.com

\section{ABSTRACT}

Objective To determine the prevalence and sociodemographic factors associated with active commuting and leisure-time physical activity (LTPA) among adults in western Nepal.

Design Cross-sectional study.

Setting Adults from semiurban areas in western Nepal. Participants 2815 adults aged 25-65 years who participated in the 'Community-Based Management of Hypertension in Nepal (COBIN)' Study. Multiple logistic regression analysis was used to identify the sociodemographic factors associated with active commuting and LTPA.

Outcome Self-reported participation in active commuting and LTPA.

Results Most study participants (96\%) commuted actively (walked or cycled) from one place to another. Our results showed that only a small proportion $(3.7 \%)$ of participants engaged in moderate or vigorous LTPA. Compared with those in paid employment, the odds of commuting actively were higher among people working in agriculture or as labourers (OR: $4.57,95 \% \mathrm{Cl}: 2.46$ to 8.48$)$, those retired/ unemployed (OR: $2.98,95 \% \mathrm{Cl}: 1.42$ to 6.25$)$ and those in unpaid employment (OR: $1.85,95 \% \mathrm{Cl}: 1.06$ to 3.22 ). Adults who were overweight or had obesity were less likely to commute actively. Compared with adults aged 25-34 years, older adults were less likely (OR: $0.35,95 \% \mathrm{Cl}: 0.17$ to 0.72 ) to engage in LTPA. Women were 0.46 times less likely to engage in LTPA compared with men.

Conclusion Most adults engaged in active commuting for work or travel. Less than $5 \%$ participated in any form of moderate or vigorous LTPA. Longitudinal studies incorporating objective assessment of physical activity and a range of individual, interpersonal, and environmental factors will help understand how to promote active commuting and LTPA among Nepalese adults. Trial registration number: ClinicalTrials.gov NCT02428075.

\section{BACKGROUND}

Transport-related physical activity, referred to as active commuting, includes using active modes of transportation such as walking or cycling to commute from one place to another. Leisure-time physical activity (LTPA) is defined as physical activities performed as part of the exercise, recreation or
Strengths and limitations of this study

A cross-sectional study with a large sample size and excellent response rate (>95\%).

- This study is one of the first papers to examine factors associated with active commuting and leisuretime physical activity among Nepalese adults, with a focus on semiurban areas in western Nepal.

- One limitation is that since data on active commuting and leisure-time physical activity were selfreported by the participants, some form of recall or social desirability bias may have occurred.

- We have focused on available sociodemographic factors and future studies may like to explore the association with interpersonal, cultural and broader environmental factors.

sports. ${ }^{12}$ Active commuting and LTPA offer a range of health, social ${ }^{3}$ and productivity benefits, including higher levels of physical well-being ${ }^{4}$ and mental well-being, ${ }^{5}$ reduced sickness-related absences, ${ }^{5}$ and decreased risk of all-cause mortality, ${ }^{6-10}$ cardiovascular disease (CVD), ${ }^{6}{ }^{10}$ type 2 diabetes mellitus $(\mathrm{T} 2 \mathrm{DM})^{1011}$ and several types of cancer. ${ }^{91213}$

The 2019 Noncommunicable Disease Risk Factors Stepwise approach to Surveillance (STEPS) Survey ${ }^{14}$ reported that LTPA contributed $7.3 \%$ and active commuting contributed $31.2 \%$ to total physical activity minutes among Nepalese adults. ${ }^{14}$ Participation in active commuting was more common in metropolitan and submetropolitan areas. The same survey found that active commuting and LTPA increased with increasing household wealth and educational attainment. Further, the participation of women in LTPA was less than that of men. ${ }^{14}$ Previous Nepalese studies have reported an age-related decline in active-commuting and negative association with higher education, marital status and unpaid employment. ${ }^{15}$

While occupational physical activity is still the major contributor to total physical activity 
among Nepalese adults, the percentage contribution has decreased from $64.8 \%$ to $61.5 \%$ between 2013 and 2019. ${ }^{14}$ Urbanisation, mechanisation and a shift from manual to sedentary occupations (such as from agriculture to deskbased jobs) are further expected to decrease occupational physical activity in the future. ${ }^{15}{ }^{16}$ In addition, the benefits from occupational activities are reported inconsistently ${ }^{17} 18$ while the health benefits of LTPA are more pronounced than other domains of physical activity. ${ }^{2}{ }^{29-22}$ Hence, there is a need to promote other domains of physical activity, particularly LTPA, even in countries like Nepal where there is relatively higher engagement in occupational physical activity.

Information on active commuting and LTPA is required to guide public health interventions targeting non-communicable diseases, including CVD, T2DM and hypertension, in Nepal and similar settings. However, studies of LTPA and active commuting among Nepalese adults are scant. This study aimed to identify the prevalence and sociodemographic factors associated with active commuting and participation in LTPA among adults in Gandaki province, Nepal.

\section{METHODS}

\section{Study design and setting}

This study used cross-sectional data collected as part of the Community-Based Management of Hypertension in Nepal (COBIN) Study. The details about the study methods have been previously published. ${ }^{23}$ We have presented the study findings following the Strengthening the Reporting of Observational Studies in Epidemiology reporting guidelines for observational studies. ${ }^{24}$ The study was conducted in Lekhnath municipality, a semiurban area located around $180 \mathrm{~km}$ west of the country's capital, Kathmandu. According to the 2011 population census, the total population of the municipality was 58816. Before federalisation, the municipality was divided into 15 smaller administrative units called wards. The municipality is a semiurban area with limited health services comprising one primary healthcare centre, three subhealth posts and two urban healthcare centres. ${ }^{23}$

\section{Study participants and data collection}

Study participants were adults aged 25-65 years who had registered for voting in Lekhnath municipality in the 2007 election. Out of the 9500 households in the municipality, 2882 households were randomly selected using the voter database. Given that the primary purpose of the COBIN population-based survey was to estimate the prevalence of hypertension, ${ }^{25}$ a sample size of 2882 was determined using the estimated hypertension prevalence of $25 \%, 5 \%$ margin of error, a design effect of $1 \%$ and $80 \%$ response rate. If any households had more than one eligible participant at the time of data collection, one of them was selected to participate in the survey using the Kish method. ${ }^{26}$ Those severely ill who could not engage in physical activity, those unable to consent, pregnant women and those unlikely to be in the study area for the intervention duration were not eligible for inclusion.

We used an adapted version of the WHO STEPS Survey questionnaire $^{27}$ to collect data on participant's demographics, lifestyle behaviours, anthropometric characteristics and blood pressure. Trained data enumerators with academic qualifications in health science (such as nurses or health assistants) used the structured questionnaire for data collection during home visits. Data were collected from 2815 adults (response rate of 97.7\%). Further details about sampling, participant recruitment and data collection are provided in the study protocol ${ }^{23}$ and previously published studies. ${ }^{28} 29$

\section{Outcome variables}

Transport-related active commuting and LTPA were the outcome variables of interest in this study. Information on active commuting and LTPA was collected using questions in the STEPS Instrument based on the Global Physical Activity Questionnaire (GPAQ). Study participants self-reported their participation in occupational, transport and leisure-time domains. The GPAQ is one of the most commonly used measures to collect population-level physical activity prevalence data in low/middle-income countries $^{30}$ and has been used previously in the Nepalese population. ${ }^{31-33}$

To determine if participants actively commuted from one place to another, they were asked: 'Do you walk or use a bicycle (pedal cycle) for at least 10 min continuously to get to and from places?' Responses were recorded as 'Yes' or 'No', and those who responded 'Yes' were considered as active commuters in this study. Information with respect to LTPA was probed using two questions: (1) engagement in any vigorous-intensity sports, fitness or recreational (leisure) activities that cause significant increases in breathing or heart rate, such as running or playing football for at least $10 \mathrm{~min}$ continuously on any day of the week, and (2) engagement in any moderateintensity sports, fitness or recreational (leisure) activities that cause a slight increase in breathing or heart rate, such as brisk walking, cycling, swimming, playing volleyball for at least $10 \mathrm{~min}$ continuously on any day of the week. Participants responding 'Yes' to any of these two questions were categorised as engaging in LTPA.

\section{Exposure variables}

The exposure variables of interest in this study were age, gender, education, occupation, monthly income, ethnicity, marital status and body mass index (BMI). Educational attainment was categorised as: schooling up to primary level, secondary and higher secondary level, and attainment of higher education. The occupational classifications were paid employment (government and non-government employees and the self-employed), unpaid employment (homemakers, agriculture and manual labour), and retired or unemployed (students, retirees and those who were unemployed). Based on monthly income, participants were classified into income 
quartiles, with the cut-offs for first (lowest) to fourth (highest) quartiles being 12000,20000 and 35000 Nepalese rupees $(12000$ Nepalese rupees $=$ US $\$ 100$ as of 26 July 2020). BMI was calculated using the height and weight measurements and categorised as underweight $\left(<18.5 \mathrm{~kg} / \mathrm{m}^{2}\right)$, normal weight $\left(18.5-24.9 \mathrm{~kg} / \mathrm{m}^{2}\right)$, overweight $\left(25-29.9 \mathrm{~kg} / \mathrm{m}^{2}\right)$ and obese $\left(\geq 30 \mathrm{~kg} / \mathrm{m}^{2}\right)$. Ethnicity was classified as advantaged and disadvantaged ethnic groups. Advantaged ethnic groups included the relatively advantaged Janajatis and upper-caste groups, while disadvantaged ethnic groups included the Dalits, disadvantaged Janajatis, the disadvantaged non-Dalit Terai caste and religious minorities. ${ }^{15} 34$ Marital status categories cohabiting and separated/widowed/divorced were merged to create 'ever married' for regression analysis. Information on sitting time was collected by asking participants: 'How much time do you usually spend sitting or reclining on a typical day?'

\section{Statistical analysis}

Descriptive statistics are reported as frequencies and percentages for categorical variables. For continuous variables (age and sitting time), mean and SD are reported. Levene's test was used to test the assumption of equal variance for independent sample t-test. We first calculated the domain-specific metabolic equivalent (MET)-minutes per week by multiplying the number of minutes of activity at each intensity by the number of days per week for the three physical activity domains (occupational, leisure-time and transport-related). We then summed the domain scores to calculate the total physical activity score and categorised them as low $(<600$ MET-min/ week), moderate (600-3000 MET-min/week) and high (>3000 MET-min/week) for descriptive analysis. We have reported median and IQRs for active commuting and LTPA-related METs-minutes per week. Bivariate associations between the exposure variables and participation in active commuting and LTPA were analysed with $\mathrm{X}^{2}$ tests. We conducted separate multivariable-adjusted logistic regression analysis to determine the associations between exposure variables (age, gender, education, occupation, income, ethnicity, marital status, BMI) and outcome variables (active commuting and LTPA). Adjusted ORs and corresponding $95 \%$ CIs are reported. A p value of $<0.05$ was considered statistically significant. All statistical analyses were carried out in Stata V.16 (StataCorp, College Station, Texas, USA).

\section{Patient and public involvement}

Since this is a secondary data analysis from the primary study (COBIN), this substudy did not involve patients or the public in the design and conduct.

\section{RESULTS}

\section{Characteristics of participants}

This study analysed the data of 2815 adults aged 25-65 years for whom complete data were available. Mean age of the participants was $45.3 \pm 10.2$ years, and women were on average 1.2 years younger than men. Women represented $63 \%$ of the sample, and $52 \%$ were educated up to primary level. Higher education levels were $14 \%$ and $2 \%$ among men and women, respectively. Working in agriculture or as labourers were the most common occupations (38\%), while $9 \%$ were either retired or unemployed. Based on BMI, $36 \%$ of the study participants were categorised as overweight, and $12 \%$ were classified as having obesity. A large majority (96\%) of the study participants commuted actively from one place to another. Among those who actively commuted, the median MET-min/week for active commuting was $1680(\mathrm{Q} 1=840, \mathrm{Q} 3=2520)$. On the other hand, only $3.7 \%$ of the study participants engaged in any form of moderate or vigorous LTPA. The average sitting time was around $180 \mathrm{~min} /$ day (table 1). There were significant differences between men and women in occupation, income quartiles, marital status, BMI, total physical activity and engagement in LTPA (table 1).

\section{Factors associated with active commuting and LTPA}

The bivariate analysis results (table 2) showed that those with primary education were more likely to undertake active commuting than those with secondary or higher education. Likewise, those engaged in agriculture or as labourers, those ever married and normal-weight participants were more likely to report active commuting. In contrast, younger adults (25-34 years), men, those educated up to higher secondary level, those engaged in agriculture or working as labourers, and those ever married were more likely to engage in moderate or vigorous LTPA.

Table 3 presents the results of multiple logistic regression analysis examining sociodemographic factors associated with active commuting and LTPA. Compared with adults engaged in paid employment, those in unpaid employment, working in agriculture or as labourers, and those retired or unemployed had 1.85 (95\% CI: 1.06 to 3.22), 4.57 (95\% CI: 2.46 to 8.48) and 2.98 (95\% CI: 1.42 to 6.25$)$ higher odds of commuting actively, respectively. Similarly, those who ever married were 3.62 (95\% CI: 1.64 to 7.96 ) times more likely to commute actively than those never married. On the other hand, compared with underweight adults, those who were in the overweight and obese categories of BMI were less likely to commute actively, with ORs of 0.46 (95\% CI: 0.29 to 0.73 ) and 0.36 (95\% CI: 0.20 to 0.66 ), respectively. No statistically significant associations were observed with active commuting and the following: age, gender, education, income or ethnicity. On the other hand, compared with adults aged 25-34 years, older adults aged 55-64 years had the lowest OR of 0.35 (95\% CI: 0.17 to 0.72 ) of engaging in LTPA. Further, women were 0.46 (95\% CI: 0.27 to 0.77 ) times less likely to engage in LTPA than men. No statistically significant associations were observed between LTPA participation and education, occupation, income, ethnicity, marital status and BMI. 
Table 1 Descriptive characteristics of study participants $(n=2815)$

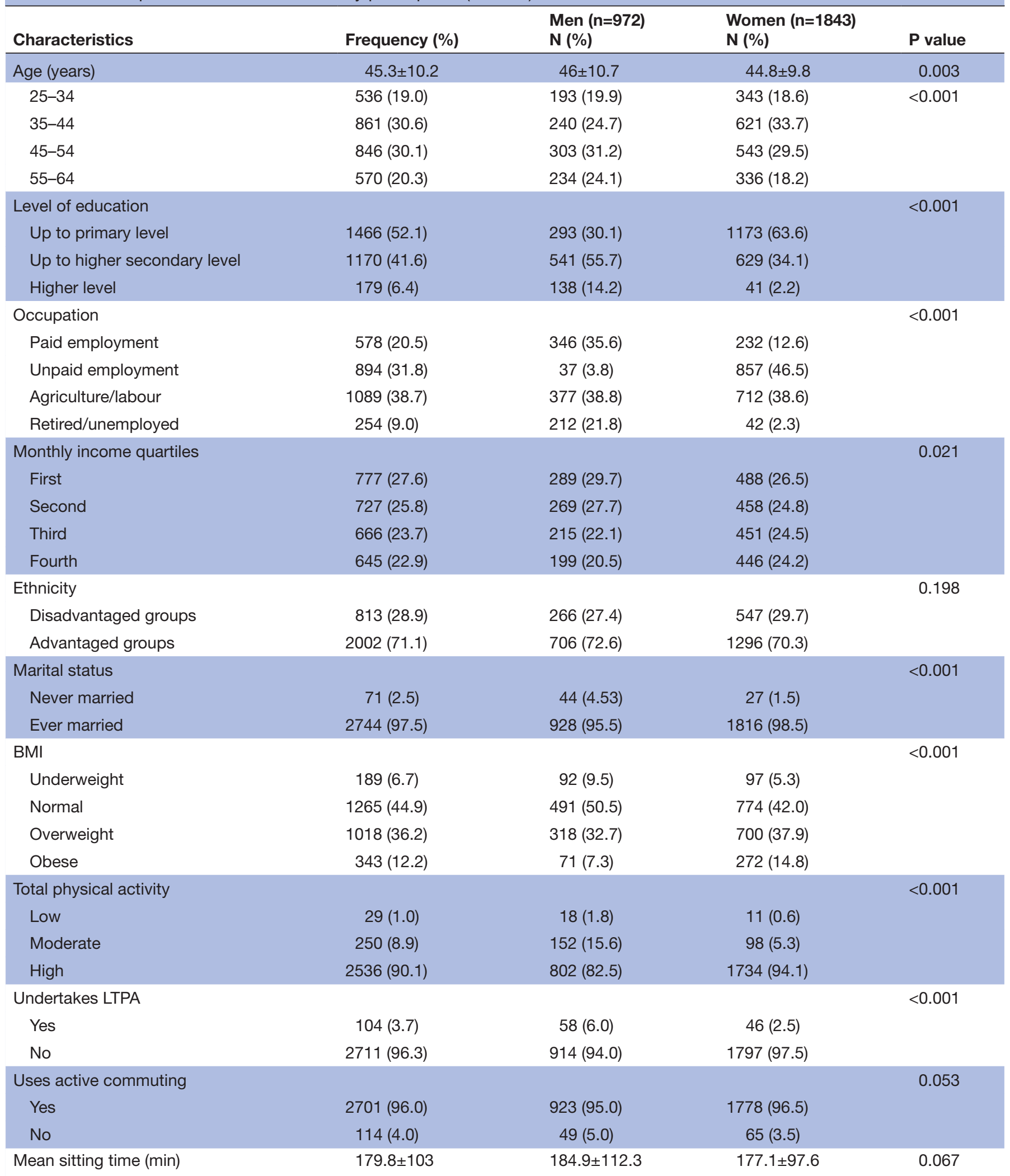

BMI, bodymass index; LTPA, leisure-time physical activity.

\section{DISCUSSION}

This study found that a vast majority (96\%) of study participants walked or used a cycle to commute from one place to another. However, the proportion of adults participating in any form of moderate or vigorous LTPA for at least $10 \mathrm{~min}$ at a time was minimal. Participation in overall 
Table 2 Characteristics of those engaged in LTPA and active commuting

\begin{tabular}{|c|c|c|c|c|c|c|c|}
\hline \multirow[b]{2}{*}{ Characteristics } & \multirow[b]{2}{*}{ Frequency } & \multicolumn{3}{|c|}{ Active commuting } & \multicolumn{3}{|c|}{ LTPA } \\
\hline & & $\begin{array}{l}\text { Yes } \\
\mathrm{N}(\%)\end{array}$ & $\begin{array}{l}\text { No } \\
\mathrm{N}(\%)\end{array}$ & $P$ value & $\begin{array}{l}\text { Yes } \\
\mathrm{N}(\%)\end{array}$ & $\begin{array}{l}\text { No } \\
\mathrm{N}(\%)\end{array}$ & P value \\
\hline $25-34$ & 536 & $504(18.67)$ & $32(28.07)$ & & 38 (36.54) & $498(18.38)$ & $<0.001$ \\
\hline $35-44$ & 861 & 829 (30.72) & $32(28.07)$ & & $25(24.04)$ & $836(30.86)$ & \\
\hline $45-54$ & 846 & $817(30.27)$ & $29(25.44)$ & & 28 (26.92) & $818(30.20)$ & \\
\hline Sex & & & & 0.053 & & & $<0.001$ \\
\hline Men & 972 & $923(34.17)$ & $49(42.98)$ & & $58(55.77)$ & 914 (33.71) & \\
\hline Women & 1843 & $1778(65.83)$ & $65(57.02)$ & & $46(44.23)$ & 1797 (66.29) & \\
\hline Level of education & & & & $<0.001$ & & & $<0.001$ \\
\hline Occupation & & & & $<0.001$ & & & 0.021 \\
\hline Paid employment & 578 & 529 (19.59) & $49(42.98)$ & & 27 (25.96) & $551(20.32)$ & \\
\hline Unpaid employment & 894 & $856(31.69)$ & 38 (33.33) & & $23(22.12)$ & $871(32.13)$ & \\
\hline Agriculture and labour & 1089 & $1072(39.69)$ & $17(14.91)$ & & $38(36.54)$ & $1051(38.77)$ & \\
\hline Retired/unemployed & 254 & $244(9.03)$ & $10(8.77)$ & & $16(15.38)$ & $238(8.78)$ & \\
\hline Monthly income quartiles & & & & 0.347 & & & 0.725 \\
\hline First & 777 & $751(27.80)$ & $26(22.81)$ & & $32(30.77)$ & $745(27.48)$ & \\
\hline Second & 727 & $696(25.77)$ & 31 (27.19) & & 29 (27.88) & $698(25.75)$ & \\
\hline Third & 666 & $642(23.77)$ & 24 (21.05) & & 23 (22.12) & 643 (23.72) & \\
\hline Ever married & 2744 & 2641 (97.78) & $103(90.35)$ & & 95 (91.35) & 2649 (97.71) & \\
\hline BMI & & & & 0.001 & & & 0.403 \\
\hline Underweight & 189 & $183(6.78)$ & $6(5.26)$ & & $3(2.88)$ & $186(6.86)$ & \\
\hline Normal & 1265 & $1233(45.65)$ & $32(28.07)$ & & 47 (45.19) & 1218 (44.93) & \\
\hline Overweight & 1018 & $963(35.65)$ & $55(48.25)$ & & $42(40.38)$ & $976(36.00)$ & \\
\hline Obese & 343 & 322 (11.92) & $21(18.42)$ & & $12(11.54)$ & 331 (12.21) & \\
\hline
\end{tabular}

BMI, body mass index; LTPA, leisure-time physical activity.

total physical activity was at a reasonable high level, though $1 \%$ did not meet the recommended levels of total physical activity (less than $150 \mathrm{~min} /$ week of moderate physical activity or equivalent). The reported prevalence of physical inactivity is lower than that reported by STEPS 2019 (7.4\%). ${ }^{14}$ Participants spent almost $180 \mathrm{~min}$ /day sitting, slightly lower than the national estimates of $201 \mathrm{~min} /$ day. ${ }^{14}$ Previous studies from Nepal have also reported a low prevalence of LTPA among adults. ${ }^{14} 1535$ This pattern is similar to other South Asian countries, as reported by a systematic review among South Asian adults that found the majority did not engage in LTPA. ${ }^{36}$ Another study from Singapore ${ }^{37}$ found that participants in full-time employment were less likely to engage in LTPA regularly. In the present study, we did not observe any association between LTPA and occupation.

Previous studies from Saudi Arabia ${ }^{38}$ and $\operatorname{Iran}^{39}$ have reported an age-related decline in LTPA participation, and older adults are less likely to engage in LTPA. The results from our study agree with this. However, a study in Taiwan has reported that age was positively related to LTPA and attributed this to an increase in LTPA in the post-retirement period (60-65 years of age). This paradox can be explained by younger adults being time-poor 


\begin{tabular}{|c|c|c|}
\hline \multirow[b]{2}{*}{ Characteristics } & \multicolumn{2}{|c|}{ OR $(95 \% \mathrm{Cl})$} \\
\hline & Active commuting & LTPA \\
\hline \multicolumn{3}{|l|}{ Age (years) } \\
\hline $25-34$ & 1 & 1 \\
\hline $35-44$ & 1.31 (0.77 to 2.26$)$ & $0.43(0.25$ to 0.75$)$ \\
\hline $45-54$ & 1.16 (0.64 to 2.10$)$ & $0.51(0.29$ to 0.90$)$ \\
\hline $55-64$ & 0.88 (0.45 to 1.74$)$ & $0.35(0.17$ to 0.72$)$ \\
\hline \multicolumn{3}{|l|}{ Sex } \\
\hline Men & 1 & 1 \\
\hline Women & 1.19 (0.71 to 1.99$)$ & $0.46(0.27$ to 0.77$)$ \\
\hline \multicolumn{3}{|l|}{ Level of education } \\
\hline Up to primary level & 1 & 1 \\
\hline $\begin{array}{l}\text { Up to higher } \\
\text { secondary level }\end{array}$ & 0.97 (0.59 to 1.59$)$ & 1.58 (0.95 to 2.63 ) \\
\hline Higher level & 0.59 (0.28 to 1.27$)$ & 1.54 (0.66 to 3.59$)$ \\
\hline \multicolumn{3}{|l|}{ Occupation } \\
\hline Paid employment & 1 & 1 \\
\hline Unpaid employment & 1.85 (1.06 to 3.22$)$ & 1.08 (0.55 to 2.14$)$ \\
\hline Agriculture and labour & 4.57 (2.46 to 8.48$)$ & 1.25 (0.71 to 2.21$)$ \\
\hline Retired/unemployed & 2.98 (1.42 to 6.25$)$ & 1.15 (0.59 to 2.27$)$ \\
\hline \multicolumn{3}{|l|}{ Monthly income quartiles } \\
\hline First & 1 & 1 \\
\hline Second & 0.99 (0.57 to 1.70$)$ & 0.86 (0.51 to 1.46$)$ \\
\hline Third & 1.22 (0.68 to 2.19$)$ & $0.73(0.41$ to 1.28$)$ \\
\hline Fourth & 1.09 (0.63 to 1.92$)$ & 0.59 (0.33 to 1.09$)$ \\
\hline \multicolumn{3}{|l|}{ Ethnicity } \\
\hline $\begin{array}{l}\text { Disadvantaged } \\
\text { groups }\end{array}$ & 1 & 1 \\
\hline Advantaged groups & 0.97 (0.60 to 1.55$)$ & $1.18(0.72$ to 1.94$)$ \\
\hline \multicolumn{3}{|l|}{ Marital status } \\
\hline Never married & 1 & 1 \\
\hline Ever married & 3.62 (1.64 to 7.96$)$ & 0.45 (0.19 to 1.03$)$ \\
\hline \multicolumn{3}{|l|}{ BMI } \\
\hline Underweight & 1 & 1 \\
\hline Normal & $0.73(0.29$ to 1.81$)$ & $0.39(0.12$ to 1.27$)$ \\
\hline Overweight & 0.46 (0.29 to 0.73$)$ & 1.32 (0.85 to 2.05$)$ \\
\hline Obese & 0.36 (0.20 to 0.66$)$ & 1.28 (0.65 to 2.49$)$ \\
\hline
\end{tabular}

Analysis is adjusted for all variables in the table.

BMI, body mass index; LTPA, leisure-time physical activity.

and juggling long working hours, caring responsibilities and economic pressure. ${ }^{40}$ Future research is needed to explore the reasons for the age-related decline in LTPA participation and to identify recreational activities that older Nepalese adults are willing to participate in. This information will be crucial to design interventions that can be quickly adopted by older adults and bring sustained behaviour change for increasing fitness levels.

Our study findings reiterate the results from previous studies from Nepal, ${ }^{1435}$ Singapore, ${ }^{37}$ Taiwan $^{40}$ and Saudi
Arabia $^{38}$ that have shown that women are less likely to engage in LTPA. This potentially could be because of the traditional gender roles that limit women's free outdoor movement. ${ }^{36}$ Further, the allocation of household and caring responsibilities primarily to women usually results in a lack of time and energy to engage in non-domestic forms of physical activity such as active commuting or LTPA. ${ }^{41} 42$ It will be vital for future interventions to incorporate strategies to address gender norms and create a supportive family and community environment to promote LTPA participation among women.

Our study results showed that, compared with people in paid employment, those in unpaid employment, working in agriculture or as a labourer, and those retired or unemployed were more likely to engage in active commuting. Lack of pedestrian and cyclist-friendly infrastructures, pollution, and/or lack of changing and shower facilities at the workplaces may also be other factors that limit active commuting among employed adults. ${ }^{354} 44$ These results are consistent with a previous study from Nepal that has reported government employees are less likely to engage in transport-related active commuting. ${ }^{35}$ In our recent qualitative study among Nepalese adults, we found that lack of infrastructure for active commuting, increased access to motorised transport, and lack of resting areas and basic amenities act as barriers to engage in transportrelated physical activity. In the same study, participants reported that the removal of these barriers would create a facilitating environment. ${ }^{16}$ Increased social support and favourable workplace norms and policies might promote active commuting, ${ }^{44}$ which needs to be further explored among Nepalese adults.

Adults who had been ever married were more likely to commute actively than those never married, a result consistent with that reported by a previous secondary analysis of the 2013 Nepal STEPS Survey ${ }^{15}$ We also found that adults in the overweight and obese category were less likely to commute actively than those who were underweight. However, because of the cross-sectional nature of this survey, temporality could not be determined, and prospective studies are recommended to understand the causal factors.

This study has several strengths to be noted. First, we had a large sample size representing semiurban areas in western Nepal. Second, there was a high participant response rate of more than $95 \%$. Third, this is one of the few studies to provide insights on the prevalence and correlates of LTPA in Nepal. However, there are some limitations that need to be considered when interpreting the results. Our study was limited to one municipality in Gandaki province. Though most of the municipalities share similar sociodemographic characteristics, the study results might not always represent other provinces of Nepal. Since active commuting and LTPA participation were self-reported by the participants, some form of recall or social desirability bias may have been present. Active commuting and LTPA are complex behavioural constructs affected by various individual, interpersonal, 
cultural and broader environmental factors. ${ }^{45}$ Still, our study has focused only on associations with sociodemographic factors. Despite our attempt to recruit a sexbalanced sample, nearly two-thirds of the participants were women. Though men and women differed in background characteristics, we were unable to run sexspecific regression analyses because of the low proportion of people engaging in LTPA, and those not engaging in active commuting.

\section{CONCLUSION}

This study found that a large majority of Nepalese adults engage in active commuting, but less than $5 \%$ participated in any form of moderate or vigorous LTPA. Paid employment, being unmarried, and being overweight or obese decreased the likelihood of active commuting. On the other hand, women and older adults were less likely to participate in LTPA. Longitudinal studies incorporating objective assessments of physical activity variables and a range of individual, interpersonal, and environmental factors will be valuable to understand additional factors that contribute to active commuting and LTPA among Nepalese adults. Future interventions might need to incorporate workplace-based strategies, address gender norms that limit women's participation in LTPA and develop tailored programmes for older adults.

\section{Twitter Narayan Subedi @nsubedi_np and Per Kallestrup @PerKallestrup}

Acknowledgements We thank all the research assistants involved during data collection and all the staff of Nepal Development Society for their key role in conducting the survey. We also thank all our study participants and local health institutions from the study sites.

Contributors SP and NS conceived and designed the study with the support of DN. SP did the literature review, analysed the data and drafted the manuscript. NS verified the analysis, contributed to drafting the manuscript, reviewed and edited the manuscript. BJS, CSM and PK reviewed and edited the manuscript. DN provided overall supervision for the study and data analysis, reviewed and edited the manuscript. CSM provided final edits to the manuscript and was involved in the original design of the COBIN Study. All authors have read and approved the final version of the manuscript.

Funding This project was a part of a project, Community-Based Management of Non-Communicable Diseases (COBIN), which was associated with a research work toward a PhD degree supported by Aarhus University scholarship. This study was partially supported by Nepal Development Society and Jayanti Memorial Trust.

Competing interests None declared.

Patient and public involvement Patients and/or the public were not involved in the design, or conduct, or reporting, or dissemination plans of this research.

Patient consent for publication Not required.

Ethics approval Ethics approval for this study was obtained from the Institutional Review Board at the Nepal Health Research Council (NHRC reference no. 1065) Written informed consent was obtained from all the study participants.

Provenance and peer review Not commissioned; externally peer reviewed.

Data availability statement Data are available upon reasonable request. The datasets analysed during the current study will be available from the last author on reasonable request.

Open access This is an open access article distributed in accordance with the Creative Commons Attribution Non Commercial (CC BY-NC 4.0) license, which permits others to distribute, remix, adapt, build upon this work non-commercially, and license their derivative works on different terms, provided the original work is properly cited, appropriate credit is given, any changes made indicated, and the use is non-commercial. See: http://creativecommons.org/licenses/by-nc/4.0/.

\section{ORCID iDs}

Susan Paudel http://orcid.org/0000-0001-7536-9476

Narayan Subedi http://orcid.org/0000-0002-8752-2244

Ben J Smith http://orcid.org/0000-0002-6227-5566

Per Kallestrup http://orcid.org/0000-0001-6041-4510

Dinesh Neupane http://orcid.org/0000-0002-1501-2990

\section{REFERENCES}

1 Annear MJ, Cushman G, Gidlow B. Leisure time physical activity differences among older adults from diverse socioeconomic neighborhoods. Health Place 2009;15:482-90.

2 Holtermann A, Krause N, Van Der Beek AJ. The physical activity paradox: six reasons why occupational physical activity (opa) does not confer the cardiovascular health benefits that leisure time physical activity does. BMJ Publishing Group Ltd and British Association of Sport and Exercise Medicine, 2018.

3 Eime RM, Young JA, Harvey JT, et al. A systematic review of the psychological and social benefits of participation in sport for adults: informing development of a conceptual model of health through sport. Int J Behav Nutr Phys Act 2013;10:135.

4 Humphreys DK, Goodman A, Ogilvie D. Associations between active commuting and physical and mental wellbeing. Prev Med 2013;57:135-9.

5 Mytton OT, Panter J, Ogilvie D. Longitudinal associations of active commuting with wellbeing and sickness absence. Prev Med 2016;84:19-26.

6 Barengo NC, Antikainen R, Borodulin K, et al. Leisure-Time physical activity reduces total and cardiovascular mortality and cardiovascular disease incidence in older adults. J Am Geriatr Soc 2017;65:504-10.

7 Cheng W, Zhang Z, Cheng W, et al. Associations of leisure-time physical activity with cardiovascular mortality: a systematic review and meta-analysis of 44 prospective cohort studies. Eur J Prev Cardiol 2018;25:1864-72.

8 Andersen LB, Schnohr P, Schroll M, et al. All-Cause mortality associated with physical activity during leisure time, work, sports, and cycling to work. Arch Intern Med 2000;160:1621-8.

9 Celis-Morales CA, Lyall DM, Welsh P, et al. Association between active commuting and incident cardiovascular disease, cancer, and mortality: prospective cohort study. BMJ 2017;357:j1456.

10 Dinu M, Pagliai G, Macchi C, et al. Active commuting and multiple health outcomes: a systematic review and meta-analysis. Sports Med 2019;49:437-52.

11 Smith AD, Crippa A, Woodcock J. Physical activity and incident type 2 diabetes mellitus: a systematic review and dose-response metaanalysis of prospective cohort studies. Springer, 2016.

12 Mahmood S, Maclnnis RJ, English DR, et al. Domain-Specific physical activity and sedentary behaviour in relation to colon and rectal cancer risk: a systematic review and meta-analysis. Int $\mathrm{J}$ Epidemiol 2017;46:1797-813.

13 Moore SC, Lee I-M, Weiderpass E, et al. Association of leisure-time physical activity with risk of 26 types of cancer in 1.44 million adults. JAMA Intern Med 2016;176:816-25.

14 Dhimal M, Bista B, Bhattarai S. Noncommuniucable disease risk factors: steps survey Nepal 2019. Kathmandu, Nepal: Nepal Health Research Council, 2019.

15 Paudel S, Owen AJ, Heritier S, et al. Prevalence of total and domain-specific physical activity and associated factors among Nepalese adults: a Quantile regression analysis. J Phys Act Health 2020;17:501-11.

16 Paudel S, Owen AJ, Smith BJ. Exploration of physical activity barriers and facilitators among adults in Kathmandu, Nepal. Qual Health Res 2021;31:1183-95.

17 Holtermann A, Schnohr P, Nordestgaard BG, et al. The physical activity paradox in cardiovascular disease and all-cause mortality: the contemporary Copenhagen General Population Study with 104 046 adults. Eur Heart $J$ 2021;42:1499-511.

18 Dalene KE, Tarp J, Selmer RM, et al. Occupational physical activity and longevity in working men and women in Norway: a prospective cohort study. Lancet Public Health 2021;6:e386-95.

19 Jurakić D, Pedišić Z, Greblo Z. Physical activity in different domains and health-related quality of life: a population-based study. Qual Life Res 2010;19:1303-9.

20 White RL, Babic MJ, Parker PD, et al. Domain-Specific physical activity and mental health: a meta-analysis. Am J Prev Med 2017;52:653-66. 
21 Wanner M, Tarnutzer S, Martin BW, et al. Impact of different domains of physical activity on cause-specific mortality: a longitudinal study. Prev Med 2014;62:89-95.

22 Bahls M, Groß S, Baumeister SE, et al. Association of domainspecific physical activity and cardiorespiratory fitness with all-cause and cause-specific mortality in two population-based cohort studies. Sci Rep 2018;8:1-9.

23 Neupane D, McLachlan CS, Christensen B, et al. Community-Based intervention for blood pressure reduction in Nepal (COBIN trial): study protocol for a cluster-randomized controlled trial. Trials 2016;17:292.

24 von Elm E, Altman DG, Egger M, et al. The strengthening the reporting of observational studies in epidemiology (STROBE) statement: guidelines for reporting observational studies. Ann Intern Med 2007;147:573-7.

25 Aryal KK, Mehata S, Neupane S, et al. The burden and determinants of non communicable diseases risk factors in Nepal: findings from a nationwide steps survey. PLoS One 2015;10:e0134834.

26 Kish L. A procedure for objective Respondent selection within the household. J Am Stat Assoc 1949;44:380-7.

27 World Health Organization. Who steps surveillance manual: the who stepwise approach to chronic disease risk factor surveillance. World Health Organization, 2005.

28 Neupane D, Shrestha A, Mishra SR, et al. Awareness, prevalence, treatment, and control of hypertension in Western Nepal. Am J Hypertens 2017;30:907-13.

29 Adhikari TB, Rijal A, Kallestrup P, et al. Alcohol consumption pattern in Western Nepal: findings from the COBIN baseline survey. BMC Psychiatry 2019;19:283.

30 Trinh OTH, Nguyen ND, van der Ploeg HP, et al. Test-Retest repeatability and relative validity of the global physical activity questionnaire in a developing country context. J Phys Act Health 2009;6 Suppl 1:S46-53.

31 Aryal KK, Neupane S, Mehata S. Non communicable diseases risk factors: steps survey Nepal 2013. Nepal Health Research Council (NHRC), 2014.

32 Khanal MK, Mansur Ahmed MSA, Moniruzzaman M, et al. Prevalence and clustering of cardiovascular disease risk factors in rural Nepalese population aged 40-80 years. BMC Public Health 2018;18:1-13.

33 Dhungana RR, Thapa P, Devkota S, et al. Prevalence of cardiovascular disease risk factors: a community-based crosssectional study in a peri-urban community of Kathmandu, Nepal. Indian Heart J 2018;70 Suppl 3:S20-7.
34 Bennett L, Dahal DR, Govindasamy P. Caste, ethnic, and regional identity in Nepal: further analysis of the 2006 Nepal demographic and health survey. Population Division, Ministry of Health and Population, Government of Nepal, 2008.

35 Vaidya A, Krettek A. Physical activity level and its sociodemographic correlates in a peri-urban Nepalese population: a cross-sectional study from the Jhaukhel-Duwakot health demographic surveillance site. Int J Behav Nutr Phys Act 2014;11:39.

36 Ranasinghe CD, Ranasinghe P, Jayawardena R, et al. Physical activity patterns among South-Asian adults: a systematic review. Int J Behav Nutr Phys Act 2013;10:116.

37 Win AM, Yen LW, Tan KHX, et al. Patterns of physical activity and sedentary behavior in a representative sample of a multi-ethnic South-East Asian population: a cross-sectional study. BMC Public Health 2015;15:318.

38 Amin TT, Al Khoudair AS, Al Harbi MA, et al. Leisure time physical activity in Saudi Arabia: prevalence, pattern and determining factors. Asian Pac J Cancer Prev 2012;13:351-60.

39 Momenan AA, Delshad M, Mirmiran P, et al. Leisure time physical activity and its determinants among adults in Tehran: Tehran lipid and glucose study. Int J Prev Med 2011;2:243.

40 Chen Y-J, Huang Y-H, Lu F-H, et al. The correlates of leisure time physical activity among an adults population from southern Taiwan. BMC Public Health 2011;11:427.

41 Saquib J, Saquib N, Stefanick ML, et al. Sex differences in obesity, dietary habits, and physical activity among urban middle-class Bangladeshis. Int J Health Sci 2016;10:345-53.

42 Mathews E, Lakshmi JK, Ravindran TKS, et al. Perceptions of barriers and facilitators in physical activity participation among women in Thiruvananthapuram City, India. Glob Health Promot 2016;23:27-36.

43 Cerin E, Nathan A, van Cauwenberg J, et al. The neighbourhood physical environment and active travel in older adults: a systematic review and meta-analysis. Int J Behav Nutr Phys Act 2017;14:1-23.

44 Bopp M, Der Ananian C, Campbell ME. Differences in active commuting among younger and older adults. J Aging Phys Act 2014;22:199-211.

45 Bauman AE, Reis RS, Sallis JF, et al. Correlates of physical activity: why are some people physically active and others not? Lancet 2012;380:258-71. 